\title{
Managing autonomy in university-industry research: a case of collaborative Ph.D. projects in the Netherlands
}

\author{
Kasia Zalewska-Kurek ${ }^{1} \cdot$ Rainer Harms $^{2,3}$
}

Received: 24 March 2019 / Accepted: 21 October 2019 / Published online: 2 November 2019

(C) The Author(s) 2019

\begin{abstract}
Research partnerships between university researchers and industry partners are becoming increasingly prevalent. For university researchers, maintaining autonomy is crucial. We explore how researchers strategically manage autonomy in collaborative research partnerships, using a framework to distinguish strategically planned and opportunity-driven behaviour in the process of selecting partners and executing research in partnerships. We then focus on the management of autonomy in setting research directions and managing the research process. We draw on insights from 14 management scholars engaged in collaborative Ph.D. research projects. Based on our analysis, we show that researcher autonomy has two facets: operational and scientific. Researchers are willing to compromise their operational autonomy as a price for industry collaboration. They have a strong need for scientific autonomy when deciding on research direction and research execution. Although they need funding, entering a specific relationship with industry and accepting restrictions on their operational autonomy is a choice. We conclude that researchers' orientations towards practice and theory affects their choices in partnerships as well as modes of governance.
\end{abstract}

Keywords Collaborative research · Management research · University-industry partnerships $\cdot$ Interdependence $\cdot$ Autonomy

JEL Classification $\mathrm{M} 10 \cdot \mathrm{I} 22 \cdot \mathrm{I} 23$

Kasia Zalewska-Kurek

k.zalewska-kurek@utwente.nl

Rainer Harms

r.harms@utwente.nl

1 Creative Technology, Faculty of Electrical Engineering, Computer Science and Mathematics, University of Twente, Drienerlolaan 5, 7522 NB Enschede, The Netherlands

2 Dutch Institute for Knowledge Intensive Entrepreneurship, University of Twente, Drienerlolaan 5, 7522 NB Enschede, The Netherlands

3 National Research University Higher School of Economics, Moscow, Russia 


\section{Introduction}

In collaboration with industry, a key goal of researchers is to produce scientifically credible knowledge (Merton 1957). Thus, autonomy about deciding on scientific aspects of research is crucial to researchers (Zalewska-Kurek et al. 2016). Threats to scientific credibility are perceived as a significant barrier to starting a university-industry (U-I) partnership (Ramos-Vielba et al. 2016). Even in collaboration where partners are carefully selected (Steinmo and Rasmussen 2015), U-I partnerships may threaten autonomy (Estrada et al. 2016).

If it is true that autonomy is under threat in U-I partnerships, then a relevant research question is: How do researchers strategically manage autonomy in $U-I$ partnerships? It has been argued that autonomy is a factor that influences researchers' performance (Trevelyan 2001). Job characteristics theory (Hackman and Oldham 1975) also underlines that autonomy is a key driver of motivation, satisfaction and performance. In U-I partnerships, strategic positioning theory is particularly salient, because it highlights the interplay between autonomy and resource dependence between researchers and industry partners (Kurek et al. 2007; Zalewska-Kurek et al. 2010).

To answer our research question, we augment strategic positioning theory (Kurek et al. 2007) by adopting an entrepreneurial process model that distinguishes between project selection and project execution (Bingham et al. 2014). We analyse how autonomy is managed in the context of resource interdependencies in the project selection and project execution phases. This research context is relevant, because social scientists' industry engagement has reached similar levels to natural scientists and engineering scientists' engagement (Olmos-Penuela et al. 2014). Research into how researchers manage autonomy may lower the barriers to U-I partnerships for social scientists.

For practitioners, our research seeks to make U-I partnerships more effective by providing suggestions on how researchers can address their key need for autonomy. Our primary theoretical contribution is the enrichment of strategic position theory by addressing its application in two phases of the U-I research process.

\section{Theoretical background}

\subsection{U-I partnership types and their implications for research productivity}

U-I partnerships include collaborative research, contract research and consulting (Perkmann and Walsh 2007). While collaborative research emphasises knowledge generation, contract research covers commercially relevant subjects. The consulting channel is mainly transactional knowledge transfer initiated by a firm. These are short-term projects that accentuate both research and commercialisation (D'Este and Perkmann 2010). Academic consulting takes many forms, such 
as research-driven consulting (when researchers want to learn and validate scientific assumptions in collaboration with industry), commercialisation-driven consulting (aimed at sharing a researcher's knowledge on developing technology), to opportunity-driven consulting (driven by monetary compensation) (Perkmann and Walsh 2008). The research shows that engaging in knowledge transfer via patenting and researcher scientific excellence (high research productivity) and entrepreneurial performance (high research budget) reinforce one another (Van Looy et al. 2004). Further, evidence suggests that applied research does not necessarily compromise basic research (Van Looy et al. 2004).

\subsection{Autonomy and strategic interdependence in U-I partnerships}

Autonomy refers to the freedom to decide on research subjects, research goals and research execution (Kurek et al. 2007). High autonomy means that a researcher is able to conduct their own research without external pressures (Zalewska-Kurek et al. 2016). However, autonomy decreases when an industry partner directs and is strongly involved in a research project (Trevelyan 2001). This reduction may be counterbalanced when a partnership involves shared goals and both partners are committed and agree on the research direction from the outset of a project.

Autonomy also decreases for those lower in the scientific hierarchy (ZalewskaKurek et al. 2016). Ph.D. researchers tend to be less autonomous, because they are usually appointed to execute a project designed by a senior researcher or a firm. Ph.D. researchers have limited scope to change the research direction. However, since they are training to become independent researchers, they should develop their competencies in research (Lee and Miozzo 2015). Ph.D. researchers seek to influence their supervisors and other project stakeholders.

Strategic interdependence is defined as the need to share heterogeneously distributed assets (resources and competences). Examples include knowledge, experience, judgment, skills, social capital, access to networks, funds, research facilities or means to publish research results (Haspeslagh and Jemison 1991; ZalewskaKurek et al. 2016). When a partner falls short in at least one of these assets, a collaboration may be sought to fill this gap. Researchers seek external funding (Wilts 2000), access to resources such as facilities (D'Este and Patel 2007) and knowledge (D'Este and Perkmann 2010). Firms seek access to state-of-the-art technologies and applicable research results (Perkmann et al. 2011). Sharing heterogeneously distributed resources is a necessary condition for any partnership (Kale and Singh 2009). Researchers and industry partners need one another's resources to accelerate innovative knowledge production (Perkmann et al. 2013).

Drawing on resource dependency theory (Pfeffer and Salancik 1978), we argue that a successful research partnership depends on the alignment of the need for organisational autonomy and the need for strategic interdependence. While resource dependency theory addresses interdependence, which includes power (Pfeffer and Salancik 1978) or mutual dependence and power imbalance (Casciaro and Piskorski 2005), we use autonomy as a central concept in academia. The degree of autonomy 
indicates the extent to which an industry partner influences a researcher's research activities.

Combinations of the need for autonomy and the requirements of strategic interdependence result in four archetypes of researchers' behaviour concerning U-I partnerships (see Fig. 1).

Mode 1 (ivory tower) researchers have a strong need for autonomy (Gibbons et al. 1994). They have a low need to access others' resources, and do not engage with industry. Instead, they remain focussed on purely academic interests. Mode 2 researchers have a strong need for external resources, but little need for autonomy. Thus, they allow industry to influence their research. Mode 2 researchers comply with an industry partner's demands rather than exerting a strong influence on research projects. Mode 3 researchers have a strong position in U-I partnerships, influencing decisions while also considering industry partners' perspectives.

To this framework, we add the dimensions of focus and flexibility. Researchers can act in a focussed or in a flexible way when selecting opportunities, i.e. research projects and partners. They can also act in a focussed or in a flexible way when they execute opportunities, i.e. carry out research (see Sect. 2.3). Since the need for strategic interdependence is high in the context of U-I partnerships-otherwise, U-I partnerships would not emerge-we focus on Modes 2 and 3 (Fig. 2). The behaviour modes provide insights into researchers' behaviours in different phases of a research partnership. By analysing the interplay between interdependence and autonomy, we can arrive at conclusions about how researchers manage their autonomy in these partnerships.

\subsection{Selection and execution in U-I partnerships}

A U-I partnership involves a dynamic process between researchers and industry partners (Estrada et al. 2016). To capture these dynamics, we used Bingham et al.'s (2014) division of the entrepreneurial process into the phases of opportunity selection and opportunity execution. According to Bingham, a firm can operate in a focussed (strategically planned) or flexible (opportunity-driven) way when

Fig. 1 Researcher behaviour modes Adopted from ZalewskaKurek et al. (2016)

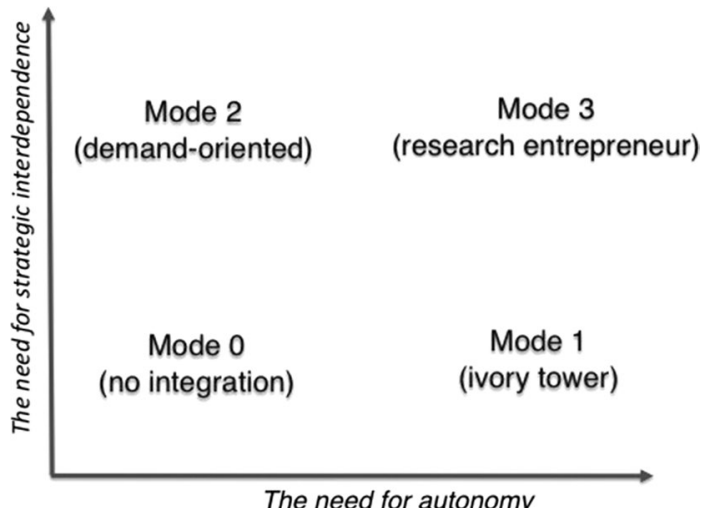

The need for autonomy 
Fig. 2 Theoretical framework

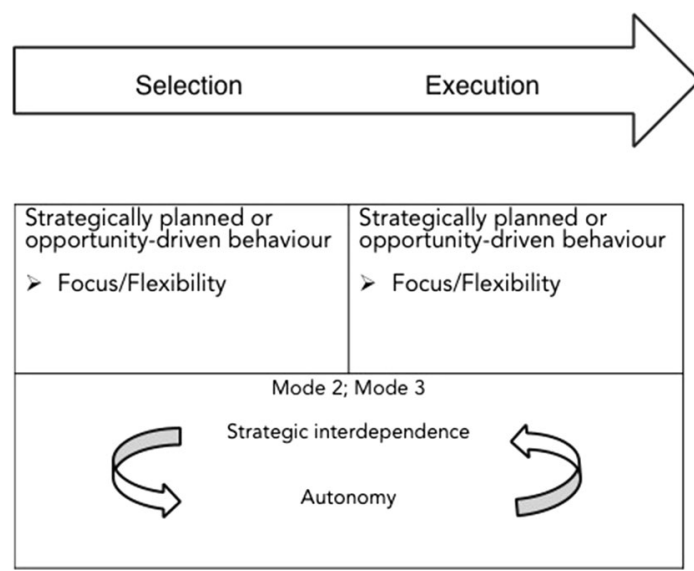

selecting opportunities to enter new markets and when executing its strategy in these new markets. We will translate the concepts of opportunity selection/execution and focus/flexibility from the business domain into the realm of researchers.

In the research context, opportunity selection refers to a researcher's choice about which partner/project to cooperate with. This can either be focussed or flexible. In focussed opportunity, a researcher selects projects or partners that fit their own strategy (based on their long-term research interests). Flexibility means that a researcher is willing to compromise research interests as long as a collaboration appears to be promising.

In the research context, opportunity selection refers to operational issues that occur in a research project, such as choices of theory, method, organisational aspects and publishing strategy. In focussed opportunity execution, the researcher initially planned most details and the execution follows this plan. Flexibility means that a researcher can react flexibly to opportunities and risks that emerge during a research project-for instance, by adapting the theory, method, organisation and publishing strategy.

We will now focus on how autonomy and strategic interdependence are managed by researchers in the opportunity selection and the opportunity execution phases. We investigate relationships between autonomy/interdependence and focus/flexibility in the two phases of a research project. We don't focus on combinations' performance implications for a sequence of research projects. Figure 2 illustrates our research model.

\section{Methodology}

\subsection{Case selection and data collection}

We collected data from a range of Dutch universities. We conducted 14 interviews with professors (lead scientists) and Ph.D. researchers as key agents in executing 
research. We analysed 11 cases (projects) from four universities (Janßen 2016). We selected the academics based on their involvement in industry-related projects. Here, industry is understood in its broader context, and includes societal partners such as commercial firms, associations of firms and professionals as well as large public national and European organisations that are organised like firms (excluding funding agencies). We used the context of management research as examples of social sciences. We aimed for heterogeneity in the range of projects, because U-I ventures vary from being purely sponsored by industry to consortia drawing on both public and private funding. We interviewed researchers who had established different partnership types with industrial partners at different engagement levels.

Some firms had a well-defined managerial problem and wanted the researcher to solve this by delivering an applicable, science-based solution. Some firms asked for a solution but were not interested in a scientific outcome. Others sought a generalised response derived from a problem at their firm they wished to understand, seeking to learn from the research insights. In some projects, researchers proposed an academically driven question that could be related to the firm.

Researchers were involved in at least one U-I project at the time of the interviews. The interviewees answered open-ended questions about one of their most recent and most representative collaborative research projects. All but one reported on a project in progress. Thus, retrospective bias was small. All projects were longterm Ph.D. projects or short-term projects embedded in Ph.D. projects.

We gathered the data in semi-structured face-to-face or Skype interviews. Before embarking on the interviews, we checked the activity profiles of academics and their websites, to become familiar with the interviewees and to prepare questions that drilled down into specific aspects of their research behaviours. We collected additional data from publication records and social media profiles (LinkedIn) to augment information about their career orientations (for instance, we checked whether they had or are currently engaged in consulting). We chose a researcher-centred perspective and did not include the industry partner, since our research question focusses on researchers' strategies (Table 1).

\subsection{Data analysis}

We applied a mainly deductive approach (Fereday and Muir-Cochrane 2006; Mayring 2000) by drawing on established theories and concepts. We used the codes (or categories) (e.g. Gläser and Laudel 2013) for the thematic analysis, as outlined in Table 2. We deduced most of the codes from our theoretical framework. This framework was then exposed to data from the semi-structured interviews and revised on the basis of the interview results.

Autonomy in the opportunity selection phase is high when the researcher determines partner selection and has a strong influence on the choice of the research topic. Autonomy in the opportunity execution phase is high when the researcher determines all aspects of executing the research, such as the choice of theory, method and results dissemination. 


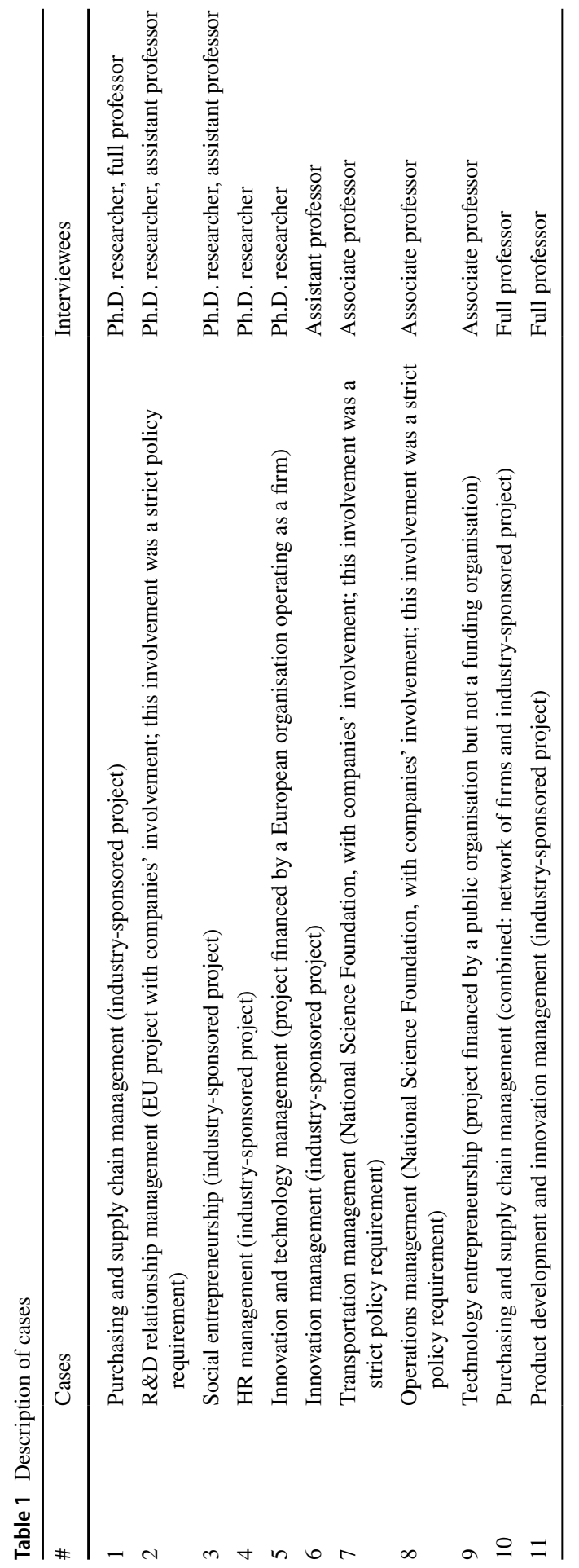


Table 2 Code manual (including both deductive and inductive indicators)

Label Strategically planned behaviour (Bingham et al. 2015)

Code 1

Definition Behaviour that focusses on the long-term planning and long-sighted decision-making of one partner with the goal of mutually enhancing their own resource base and achieving specific goals

Description A focus chosen by a partner that is characterised by a long-term perspective on the part of the researcher and goal attainment. Formalisation supports the strategic focus

Indicators Reason to choose the partner was the good fit with the own research programme; low willingness to compromise in terms of research direction and outline; disagreements that indicate distinct goals and strategies followed by partners

Label Opportunity-driven behaviour (Bingham et al. 2015)

Code 2

Definition Behaviour that is driven more by the short-term capturing of emerging opportunities and that focusses, besides mutual value creation, on more direct valorisation of project deliverables for both sides of the partnership

Description Opportunity potential as a driver makes a partner act with greater flexibility and adaptive response. Less formalisation allows for manoeuvrability in the execution phase

Indicators The reason to choose the partner was not only the fit with own expertise; great willingness to compromise in terms of research direction and outline

Label Strategic interdependence (Zalewska-Kurek 2016)

Code 3

Definition Each partner's dependence on the counterpart's resources, assets and capabilities

Description High degree: a reciprocal relationship with mutual dependencies. Sharing many resources.

The industrial partner sponsors research; provides access to data

Low degree: a unilateral relationship, with the greatest benefit for one partner. The researcher does not depend greatly on the firm's resources to undertake the research

Indicators The need for strategic interdependence is indicated by the need to access resources, assets and capabilities without which researchers could not perform their research. Examples of resources and capabilities are internal data access, financial resources, access to organisational facilities, access to contacts, social networks, skills and knowledge of both the organisation and the researcher

Label Autonomy (Zalewska-Kurek 2016)

Code 4

Definition The researcher's freedom to decide on the research direction and to conduct the research, but with the (continuous) support of the firm and the environment

Description High degree: having full power and influence over the decisions concerning research direction and the execution of the research

Low degree: the industry organisation influences the context and the research directions by making decisions; the research takes place within highly formalised boundaries

Indicators Who makes decisions on the research direction and project outline; who proposes changes; time spent on activities not directly related to the joint project but required by the partner; confidentiality clauses and other influences on an intended publication; frequency and content of progress meetings on the project; the researcher's independence in conducting the research (e.g. deciding on the method); the extent of practitioner-oriented deliverables offered by the researcher 
Strategic interdependence of the researcher is high in the opportunity selection phase when there is a promise of a reciprocal exchange of research resources. In the opportunity selection phase, strategic interdependence is high if there is an de facto exchange of resources.

We then translated the concepts of strategically planned and opportunitydriven behaviours (Bingham et al. 2014) into the research project levels. Strategically planned behaviour in the opportunity selection phase means that researchers approach a firm to join or initiate a project that fits their specific long-term research programme. Opportunity-driven behaviour in the opportunity selection phase is indicated by acceptance or initiation of a project that falls within the researcher's competencies but may not reflect long-term research interests. Strategically planned behaviour in the opportunity execution phase is indicated by a research process that deviates little from what was initially planned. Opportunity-driven behaviour in the opportunity execution phase refers to a research project that exhibits flexibility.

We also allowed for new categories to emerge (inductive element) (Fereday and Muir-Cochrane 2006; Mayring 2000). An interesting category emerged from the interviews: time spent on activities not directly related to the joint project but required by the partner. It came to our attention when hearing about Ph.D. researchers who were embedded in companies and were required to spend time working for the firm, to the detriment of their research. We expanded our analysis with this category.

\section{Results}

\subsection{Opportunity selection phase}

\subsubsection{Autonomy and opportunity-driven project selection}

Autonomy in choosing the collaborations seemed to drive the researchers' project selection. For instance, researchers who seemed more practice-oriented often engaged in consultancy projects or integrated (short-term) consultancy projects into their research. These quotations exemplify such behaviour. Asked how he selects research projects, a senior researcher replied:

I am always very open-minded. And sometimes people trigger me, and people are triggered by me and then something might happen. So as an academic to increase fortune, you should be a very active networker. You should go to meetings, you should go to conferences (R7: 61-64).

In ten percent of the cases, I am the one who goes out and invites people [to join a research project]. In eighty to ninety percent of the cases, I am being invited. And then it depends on your capacity and your real interest, and on the energy that you feel with a person, whether you engage with that person on that project or not. (R7: 74-77). 
So, these younger colleagues say to me ' $(\ldots)$ is this going to lead to any publication?' and I said: I don't know; I know we are going to do a survey which has a practitioner relevance; it isn't very theory-driven, but it creates a lot of contacts (R7: 89-91).

It's not always the case that you can do research that leads to publications. Sometimes you have to do other research which leads to money, to income, but doesn't necessarily satisfy the basic needs of an academic in terms of publication (R7: 106-109).

This researcher (R7) is fairly opportunity-driven when deciding on which projects to accept. Although he describes a project's appeal along with the other partners' engagement as a catalyst for collaboration, his long-term planning was not defined. He intentionally keeps his long-term perspective open and wide in scope. He also sees contract research as an opportunity to generate further contacts for prospective research (R7: 89-91).

Opportunity-driven researchers often had a broad perspective on what constitutes an opportunity. They were willing to accept proposals for research that fitted their loosely defined research interests rather than a specifically designed research programme. For instance:

He explained some of the things that they were working on and that fits to some extent pretty well with what I'm doing. So, we went by that organization to discuss what they were doing and what their future development were etcetera. And then along the way we found that, or we basically asked: what can we do together? (R12: 8-12).

\subsubsection{Autonomy and strategically planned project selection}

Theory-driven researchers more often engaged in projects that fitted their long-term research programmes. They showed strategically planned behaviour. For instance:

There are many, many research opportunities out there. So, if you really like sort of going after the opportunity, you probably end up with all kinds of research projects that are not really in line of what you actually want to do. So, I am always very careful in what I do, in which projects I actually accept for companies. And if they don't fit my own research interest, my research lines, I am not going to do them (R8: 392-396).

There is a difference between the cases observable in the decision-making process on whether to engage with a firm on a certain project as well as on the strategic orientation. The abovementioned researcher (R8) showed strategically planned and autonomous behaviour in choosing only research projects that suited his area of expertise and core research. He had clear expectations on how a project should generally be outlined. He anticipated that his contribution would remain theoretical without designing managerial interventions to be executed within the firm. The interventions were the responsibility of the firm or a consulting business mandated by the firm. In addition, R8 makes a project conditional on the research 
being published and with no obligation on him to engage in contract research. This requirement can be connected to this researcher's belief that universities and their research programmes are increasingly influenced by firms, which can have a detrimental effect on researcher integrity.

\subsubsection{Autonomy and mixed behaviour in project selection}

Strategically planned and opportunity-driven behaviours form two ends of a continuum. The two researcher types we presented demonstrate clear-cut behaviours. However, most respondents fell somewhere between these two ends. A few researchers agreed to specific projects that were close to their research area because they offered money for a new Ph.D. researcher and, in the end, would provide scientific output. In sum, new projects and new publications would lead to new knowledge.

In a competitive research funding landscape, researchers may be opportunitydriven. On the basis of our observations and knowledge of the science system, rather than explicit statements from respondents, we identified career stage as a factor that affects researcher behaviours. The boost Ph.D. researchers can give to scientific production is an additional resource for more senior researchers. Ph.D. researchers are seldom employed full-time by a university in joint projects. In U-I projects, an agreement is often made that a Ph.D. researcher will work part-time for a firm. For instance:

And then we said that maybe it would be beneficial if they would have someone working there, who is also, next to working there, is also an advisor also does $\mathrm{PhD}$ research. So, two days a week for $\mathrm{PhD}$ research, three days a week just doing actual work. But of course, there is an overlap between the two (R12: 12-15).

$\mathrm{Ph}$.D. researchers also display either strategically planned or opportunity-driven behaviours when entering their Ph.D. trajectory. Their role in the process should not be omitted. All interviewed Ph.D. researchers were interested in their research's practical relevance. However, the respondents with an academic career orientation struggled with the work they were required to perform for a firm. Those with a practical career orientation accepted practically oriented projects, and there seems to be no friction. In particular, they accept a firm's operational work conditions. Such work is part-time work for a firm, to solve its problems, and work on company projects not necessary related to their own Ph.D. project. For instance, a Ph.D. researcher said:

I have little academic ambition in fact. So, publishability is not a big matter for me, specifically. My supervisors like it, but I think by now they also understood that it's better to let me do what I want to do than try to put something out of it. And what I want to do is I want to help this organization which really has a problem, or rather I would say has an opportunity actually. (PhD6: 12-17). 


\subsection{The opportunity execution phase}

\subsubsection{Focus and flexibility}

The researchers were fairly flexible and opportunity-driven concerning research execution. One reason was that their projects were often not clearly defined ex ante. If there was no clear agreement on the research direction, there was scope for ambiguity and friction, which intensified in the project's execution phase.

Researchers could be focussed (strategy-oriented) in this phase in terms of operations such as formalised deliverables, but remained flexible (opportunitydriven) in terms of conducting research (e.g. data collection). This suggests that their autonomy has two facets: operations and academic freedom. Our data also show that strategically planned behaviour-research goals set in the opportunity selection phase-remained unchanged (strategy-driven opportunity selection) but could be executed flexibly (research subgoals and conduct), notwithstanding the high formalisation required by a firm. We will now elaborate on flexibility and provide examples when analysing researcher autonomy.

\subsubsection{The need for autonomy}

In the opportunity execution phase, researchers maintained significant autonomy. However, some projects were more formalised than others, and researchers had to comply with the partnership agreements. Formalisation is usually related to process rather than content. Researchers were fairly flexible concerning content, but were nonetheless required to report their findings to a firm. For instance, some projects had a clear plan with objectives, deliverables and prearranged evaluation meetings, while others had a structure that was less strict and less clearly defined. Particularly in relation to the content:

We had a generic idea and a good hunch that we could setup an interesting project. But we didn't set it in stone, so it was more like an organic way. Because there were quite some risks in the project. So, there was the risk that we could not develop the tool or had no tool. It all went well; we also got access via another firm to a huge database with customers. So, actually, it was a risky project in a sense that the outcome dependent on the input of at least four firms. (R4: 110-115)

In relation to the process, researchers tended to be in charge of setting milestones and leading the process:

It's our project, completely ours, because you saw it already in the first meeting we had. We were setting the meeting, and they okay, just come', we made the presentations, we said these are the three studies, and it was all fine. And the student thought 'what will they think about, what are the requirements'. We set the requirements (R9: 123-127). 
Formalisation concerned a general project outline, its feasibility and matters of practical implementation. A researcher pointed out that if formalisation was too strict, this could harm the research process: formalisation tends to be timeconsuming and limits the ability to react flexibly to contingencies.

Because, in all research projects, you get deviations from what you actually set out to do, and the more you formalise in the beginning, the more you get into this kind of 'This is not what we supposed to do', 'no, because we couldn't do this, because you didn't have the data' or 'we changed this'. So, it's like a new product development project; the more you formalize in the beginning the less degrees of freedom you have and the more friction you get at some point during the process (R8: 250-255).

Further, it is often not possible to formulate a specific research outcome ex ante. Instead, there should be consent on the research subject and how the research is to be conducted, so that data sources can be identified. To access data, a project partner's hierarchical position is key. A high hierarchical position fosters data collection via easier approval mechanisms and the need to involve fewer employees. An interviewee stated that discussions with firms during research projects tend to be confined to questions concerning necessities and firms' desire to expedite a project. Also, it is often difficult for company partners to offer input on subjects with high abstraction and high complexity. In response to these constraints, regular feedback meetings were held to ensure coordination. However, informal meetings between a researcher and a company representative were much more frequent, and served as a mechanism for socialising within the firm and project coordination. Such coordination is necessary for the effective deployment of complementary resources.

It is key to reach agreement in the initial stage of a partnership. Our interviewees indicated that they were able to achieve a shared understanding with their partner early on. Most firms realised that the openness of research requires identification and resolution of issues along the execution of a research project. The outcomes of research cannot be predicted, and research direction may change owing to better theories or simply the availability of data.

You should be very careful that the industry is not dictating what you research and how you do this, because then they will also get a say or an impact on what you are actually allowed to report and not to report. You should always maintain your academic integrity in this instance (R8: 450-453).

In (only) two cases was the research direction and firms' expectations too vaguely defined, or did a firm implicitly expect consulting services. This led to ambiguity or friction. In a case without clear research directions, the researcher reported a high interference by the firm in research, describing it as very bureaucratic and hierarchical, with very formal procedures. The firm also had no experience with research publications. This led to more control from the firm.

We will now consider autonomy in relation to scientific integrity. Formalisation of a partnership was not seen as destructive but facilitating if the research 
methodology was not compromised. The interviewees specified the need for a shared understanding of the project outline, a clear focus that eliminated distractions and generated commitment, and consent among partners on how to conduct research with high autonomy levels assured.

Autonomy may be restricted by an industrial partner in the selection phase. This was the case in two short-term projects. Here, each firm wanted a solution to its problems (practice-oriented projects), yet the researchers enjoyed autonomy in the execution phase, since the firms did not interfere with the research methodology. However, this was not the case for all Ph.D. researchers. There were embedded in projects that were already designed, and depended on their supervisors and on their industry partners for financial support and data to conduct their research. If they were embedded in a firm, their autonomy was more restricted than that of their supervisors in relation to the industrial partners. Ph.D. researchers-in return for receiving finance for a Ph.D. trajectory-are often required to work part-time for a firm, or to maintain a physical presence at the firm. They often engage in operational tasks or other projects that are not always related to their research interests. This means less time for research and publishing, infringing on a researcher's autonomy:

What I know from my PhD student, in the beginning she really liked to be there. So, she liked to have this both doing more practical things and doing the research. But after time, she got fed up with it, because she had this urgency of 'okay now, I have to do a couple of things'... But it was also for example that she really wants to publish, and the entrepreneur is not really interested in that... and wants more practical things. And, of course, the pressure increases of getting her scientific deliverables at a certain moment. That kind of diverted. But in the beginning, in fact, the entrepreneur was her objective study, so, for her, it was wonderful to be there. It is not only doing an interview; she was there and she could observe what happened, etcetera. So, she really liked that part for that reason, but at a certain moment, she knew how it was going. And there was always more practical work, which also kept her from a couple of other things (R11: 133-143)

One $\mathrm{Ph} . \mathrm{D}$. researcher struggled to manage the expectations of both the academic and the industry partners (in this case, several firms and organisations) in the project. This negatively impacted on his research and restricted the time he could spend on delivering academic output.

I think that such a project [a PhD project] is loaded with confusion, because first of all you start with twenty different stakeholders, expecting different things from such a project. And because it is abstract, you can't really manage those expectation, because it's not really clear what is going to happen. And I think there is a really large gap between what is academically relevant and what is practically relevant. The same goes for what is academically accepted and what is practically accepted. So, I have two academic supervisors and some stakeholders in the organisation, and I make sure that, 
through engagement with them all, that they all know what I'm doing, what

I'm going to do and what they can expect (R5: 131-139).

In one case, a supervisor and a Ph.D. researcher had different perceptions concerning part-time work. The senior researcher said "there is an overlap between the two" (R12: 15), while the Ph.D. researcher claimed that the work was simple operational work that was entirely unrelated to his Ph.D. Apparently, the senior researcher's expectations were not in line with what had been discussed in the opportunity selection phase. The Ph.D. researcher, whose ambitions were academic rather than applied, became dissatisfied.

Sharing time between a university and industry caused delays in Ph.D. projects. Delays in Ph.D. processes also resulted when the industry partners did not deliver what they had promised or when they asked for additional tasks to be undertaken. On the other hand, embedding Ph.D. researchers in collaborative projects was a key consideration, since Ph.D. researchers have competences that are valuable for all partners in a partnership.

Another factor that delays research projects is the requirement that papers based on firm's data are sent to the firm for approval prior to submission to a conference or journal.

If we write a paper, we always send it to the firm... 'This is what we are going to submit. Do you agree? Yes or no?' Not content-wise, because that is out of the discussion, but in the way that for example, the business setting or the firm setting is described (R8: 355-362).

While firms did not ask for information to be deleted from papers, it took them long to process these papers. This requirement stems from the confidentiality the firm demands: the data has to be treated anonymously. Confidentiality was an issue in only two projects. One example was a project with a multinational corporation that had clear guidelines to postpone research publication for a certain period.

\subsubsection{The need for strategic interdependence}

All the relationships that the interviewees entered into with industry were driven by the need for resources. Access to data (i.e. a firm's database, client contacts and data collection via interviews) were regarded as the key contribution offered by a firm. One researcher noted that data quality and availability is even more important than the funding.

Data access is the most important asset they gave us. Even in this case, that if they didn't finance the research position, the $\mathrm{PhD}$ position, then we would still go ahead with financing for the $\mathrm{PhD}$ in any other way, because, you know, getting financing is less difficult than finding good data access (R8: 82-85).

In (only) two cases did a firm's employees create difficulties by delaying, restricting or blocking access to data, with negative consequences for the researchers. In seven projects, firms shared not only their data, but also their network and contact 
information. This was very valuable to researchers. Most projects were financed or co-financed by firms. While firms in most cases contributed financially to a project (not necessarily financing the whole project), further contributions were mostly based on data provision and access to further contacts that were valuable to the researchers. Although companies that host Ph.D. researchers were expected to be supportive and amenable in providing help, for instance in understanding their (research) problems, this was not the case in all circumstances. A Ph.D. researcher, when asked about the firm's contribution to the Ph.D. process, said:

Yeah, well, that's the difficult thing... I am the only academic working there. That makes it very difficult, I think, because they don't understand really the university and the academic world and how research is conducted. I wanted to explain it to them, but it's very hard. I mean, they don't understand. And I am the first PhD there (PhD2: 105-108).

Firms that engage in a U-I project are expected to provide not only financial resources and data but also time, support and commitment. Researchers who received such commitments were more enthusiastic, not only about their own research, but also their work for their firms. The interviewees generally indicated that firms that sponsor research projects usually engage and commit to them as researchers. This is demonstrated not only through existence of communication channels and evaluation meetings, but also through the interest and involvement of top managers in both the selection and execution phases. On the other hand, we observed lower commitment from firms in cases when they were asked to join a consortium to fulfil National Science Foundation requirements.

And I think still today we notice that... I think there is one particular firm that we work together the most. But for the other ones it remains a little bit hard to keep them on board, to keep them interested. We had another network meeting, two months ago; again, not all parties were presented, but most of them were present; also, the big corporations were there. Especially the multinational corporation leading in building wind farms is for us important party, not only because it is a big and important firm, but they are basically the firm making the decisions that we are actually focusing on in our research (R13: 255-262).

These partners showed less interest in the research process-even though they are committed personally committed (and through the allotted work hours) to this project - and tended to wait for the valorisation of results.

The researcher contributions ranged from conceptual thinking and theory development to determining organisational factors relating to a firm's problem. For some researchers, the project outcome is the point at which termination of negotiations or the contract is considered, since elucidation of a research problem coupled with a scientific publication is the primary motivation, and this has now been fulfilled. Other researchers extended their contributions to the more practical aspects of implementation, leading sometimes to consulting services. In many cases, researchers sought to comply with the demands of both their academic 
goals and a firm's interests. For instance, one researcher was interested in innovation management, based on his involvement in resolving a practical problem and his academic interest in advancing knowledge in innovation management.

Well, they've developed a product, they don't have that much knowledge about how to interact with the customer and let them design their own home, but it could be useful in that setting as well. So, I had a research question, I thought it could them in maturing their concept. So, we just contacted them, and they were interested (R4: 26-30).

To simultaneously deal with the expectations of companies in delivering practical value for a firm and scientific output for the research community, researchers engaged Master's and Bachelor students working on their final assignments. These additional resources allow researchers to focus on the academic aspect of research. Thus, short-term deliverables can be provided to a firm, as underscored by an interviewee:

(...) if you have a good student, it catches some low-hanging fruits, yeah, companies are happy. Not everybody sees the difference between more consultancy-like work of a Master's student and real scientific stuff. You know that most companies are short term thinking, so if they get some short-term results, they're happy. So, if you make some kind of combination of Bachelor or Master's students and a $\mathrm{PhD}$ student, who also take care that papers are written, that works pretty well so far (R14: 97-102).

This action can be seen as a strategy aimed at gaining more time and exerting less pressure on delivering specific solutions to industry, which can facilitate greater autonomy for researchers.

\section{Discussion}

Our research question was to identify how researchers strategically manage autonomy in U-I partnerships. We analysed the interplay between autonomy and interdependence, developing a framework that distinguishes between strategically planned and opportunity-driven behaviour in the partner selection process (opportunity selection phase) and executing research in partnerships (opportunity execution phase).

In both the opportunity selection and opportunity execution phases, we observed systematic patterns in researcher behaviours (see Table 3). Very few researchers seemed to be purely opportunity-driven. Most researchers had a strategy to advance their research in a specific field and occasionally accepted an offer from industry, as long as it doesn't divert them from their strategy. We assume that this is due to their goals and the way researchers are assessed. In the science system, promotion for researchers depends on the quantity and quality of their publications. Thus, it is in their best interest to engage only in partnerships that add to their career goals. 
Table 3 Summary of the main results

\begin{tabular}{|c|c|}
\hline Selection phase & Execution phase \\
\hline $\begin{array}{l}\text { Autonomy in choosing collaborations that first } \\
\text { meet the research interest seems to drive the } \\
\text { researchers' project selection } \\
\text { Project selection was mostly strategically planned } \\
\text { or on that end of the continuum } \\
\text { Pure opportunity-driven strategic behaviour was } \\
\text { less present; some research subjects or fields } \\
\text { involved practitioner-oriented deliverables } \\
\text { The contact was mostly established owing to a } \\
\text { researcher's network rather than a formal selec- } \\
\text { tion process } \\
\text { In most cases, there was an agreement between } \\
\text { project partners concerning the research direc- } \\
\text { tion and project deliverables, which set a project } \\
\text { focus and minimised ambiguity or friction }\end{array}$ & $\begin{array}{l}\text { Researcher autonomy increased in the project execu- } \\
\text { tion phase, particularly owing to the trust earned } \\
\text { from the firm } \\
\text { We distinguish between two autonomy types: opera- } \\
\text { tional (concerning formalisation and operational } \\
\text { management of projects) and academic (scientific } \\
\text { integrity, methods, etc.) } \\
\text { Researcher operational autonomy was medium or } \\
\text { high } \\
\text { Academic autonomy was fairly high, since decision- } \\
\text { making and seeking agreement were seen as an } \\
\text { organic path through which the mutual outcome } \\
\text { focus of partners would resolve dissimilarities } \\
\text { along the way } \\
\text { Strategic interdependence among all researchers can } \\
\text { be seen as medium to high } \\
\text { Strategic interdependence was maintained owing to } \\
\text { agreement on a focused research direction, flexible } \\
\text { research conduct, and the partners' general com- } \\
\text { mitment to the project deliverables } \\
\text { Ph.D. researcher autonomy was constrained by the } \\
\text { project boundaries. Their autonomy was more } \\
\text { limited than that of their supervisors in relation to } \\
\text { the industrial partners if they were embedded in } \\
\text { the partner organisation } \\
\text { Valuable outputs for all partners can be generated } \\
\text { via both academically accepted and practitioner- } \\
\text { oriented project deliverables within the scope of } \\
\text { the particular research collaboration and support- } \\
\text { ing Bachelor and Master's level projects }\end{array}$ \\
\hline
\end{tabular}

Our data suggest that strategically planned and opportunity-driven behaviours relate to a researcher's vision and strategies. Purely practice-oriented researchers engaged enthusiastically in projects driven by company-specific problems. They were motivated to deliver quick solutions to these problems, even if this delayed their research agendas. These researchers saw such projects as opportunities that could result in publishable results, yet publishing was not the primary goal at this point. On the other hand, theory-driven researchers engaged only in projects that guaranteed academic freedom and that would lead to publishable output. They accepted projects that would contribute to their strategic goals. Therefore, we postulate:

Proposition 1: Practice-oriented researchers are more likely to select projects in an opportunity-driven way, while theory development-oriented researchers will select projects in a strategically planned way.

This proposition, based on the pattern reflected in our cases, is consistent with Ramos-Vielba et al. (2016), who found that researchers that seek to apply knowledge collaborate with firms, while researchers who want to advance knowledge will more likely collaborate with government agencies. Nonetheless, we argue that 
practice-oriented researchers not only strive to apply knowledge but may also seek to advance it. Thus, depending on the project, they could be placed in both the Pasteur quadrant (quest for fundamental understanding and high consideration for use) and the Edison quadrant (low quest for fundamental understanding and high consideration for use), according to Stokes (1997). Further research should validate this proposition, since it somewhat contradicts a proposition by Perkmann and Walsh (2008) that engaging in opportunity-driven and commercialisation-driven consulting does not affect a researcher's choice of more applied research. We assert that researchers only engage in such projects when they already have an established interest in applied research. Researcher orientation may also have consequences for their careers. As the research shows, physics and engineering Ph.D. researchers' engagement in industry projects negatively affected their career in academia; however, it increased their chances of a career in industry (Lee and Miozzo 2015).

In the opportunity execution phase, researchers behaved mostly in Mode 3 (strong needs for both sharing resources and autonomy). Researchers may have to relinquish some autonomy when they accept the terms of collaboration with industry, but they have a strong need for autonomy when they decide on the research direction and research execution. Although they need to obtain external funding, it is their choice to enter a specific relationship with industry and accept resulting restrictions on their autonomy. Restrictions on scientific credibility are seen as the major barrier to collaborative projects (Ramos-Vielba et al. 2016). Thus, we conclude that there are two facets of researcher autonomy: operational and scientific.

Operational autonomy pays considers all the issues related to planning, communication with the industrial partner, and setting and executing milestones. Scientific autonomy relates to matters such as methodology, theory and uses of results. We note that researchers give up some autonomy, in this case operational autonomy, in exchange for heterogeneous resources. This observation gives weight Salimi et al.'s (2015) finding that those who control critical resources tend to centralise governance of collaborative Ph.D. projects.

We argue that giving up some operational autonomy may help in managing both partners' expectations and to preserve the envisioned focus. An example of formalisation would be setting goals, milestones and frequent meeting schedules in conjunction with executing such a plan. This could limit delays and could lead to a succession project completion. Contrary to Bingham et al. (2014), we conclude that researchers who are not diverted from their main research direction in the execution phase by environmental factors (that is, not flexible but focused in terms of operational autonomy) are more likely to successfully complete a project.

Proposition 2a: Researchers will give up some operational autonomy, i.e. accept some formalisation in setting clear goals and in instituting a delivery plan in the selection phase, and they will manage both partners' expectations in the execution phase, if the perceived benefits of formalisation are high.

At the same time, in line with Bingham et al. (2014), we argue that researchers who enjoy scientific autonomy and have the flexibility to choose how to execute research in the execution phase will perform better, since there is no pressure (Zalewska-Kurek et al. 2010). Bingham (2009) argues that firms are-over 
multiple market entries-more successful when they use a focussed approach to opportunity selection and a flexible approach to opportunity execution. Greater focus in selection leads to improved learning by linking (comparable) experiences over time. Greater flexibility in execution allows firms to adapt to market conditions that remain unique, even when the opportunities have been selected in a focussed way. We argue that the mechanisms of learning and the benefits of flexible execution are fundamentally the same in research projects concerning scientific autonomy. Thus:

Proposition 2b: Researchers with high scientific autonomy and, thus flexibility, will perform better and are more likely to complete collaborative projects on time.

Accepting more influence on research, and Mode 2 behaviour, could be a strategic choice not only for researchers who want to translate scientific knowledge into practice and to solve practical problems. Some researchers indicated that they were willing to accept certain projects and greater restrictions on research in the short term to secure resources that would advance their research in the future. This would be an indication of their long-term strategic thinking. Based on these findings, therefore:

Proposition 3a: Researchers are willing to accept more influence and restrictions on their autonomy from industrial partners to gain resources for their future research.

Proposition 3b: Researchers are willing to accept more influence and restrictions on their autonomy from industrial partners to build trust with the industrial partner and have greater autonomy in the future.

Joint research with industry tends to increase research output and to generate research with greater impact (Agrawal and Henderson 2002; Louis et al. 1989; Van Looy et al. 2004), because researchers obtain access to-normally inaccessibleresources and use industry as a means to knowledge production (Zalewska-Kurek 2016). However, not all engagement types with industry are seen as enhancing productivity. For instance, Perkmann et al. (2011) argue that opportunity-driven consulting leads to a decrease in research productivity. We observed yet another aspect of consulting research that concerns the situation of Ph.D. researchers embedded in such projects. More senior interviewees who engaged in consulting/opportunity-driven projects were fairly enthusiastic about new opportunities, while Ph.D. researchers who had to perform this research type were less eager. Industry projects give Ph.D. researchers lower autonomy, since Ph.D.s are tied to a specific project and must often deal with the expectations of industry and academia, a ready source of tension. Ph.D. researchers were also under greater restrictions if they were deeply embedded in the funding firm. This finding has practical implications for those who wish to pursue a Ph.D. trajectory. Based on our observations, restrictions on autonomy in projects seeking to solve practical problems can lead to delays and can therefore jeopardise the success of otherwise fruitful partnerships (e.g. not reaching initial goals). We argue that: 
Proposition 4: Opportunity-driven behaviour leads to consulting-driven projects and delays research (less successful research partnerships).

The execution phase makes clear whether or not the industrial partner is committed to the project. Our data showed that firms that are interested in research results from the start of the project spent more time communicating with the researchers. These firms showed greater involvement and commitment, and guaranteed academic autonomy. As seen in the strategic alliances literature, the company leaders' commitment is a necessary condition for success in an alliance (i.e. for attaining all the alliance's goals and objectives) (Kale and Singh 2009). Mora-Valentin et al. (2004) showed that commitment as well as involvement, trust, communication and clear objectives are key to U-I partnership success. These results allow us to advance the proposition that industry partners' commitment and involvement take precedence over their need for academic knowledge and certain research outcomes (as well as other resources for researchers):

Proposition 5: A stronger need for strategic interdependence (resources) by the industry partner leads to greater involvement and commitment by this partner, and thus to more successful U-I research partnerships.

\section{Conclusion}

\subsection{Implications}

The main conclusion of this study on the strategic management of autonomy in U-I partnerships is that the choice of collaborative U-I projects is primarily driven by researcher autonomy and their strategic orientation. They may be willing to give up certain aspects of their autonomy. To understand which aspects, we distinguished between operational autonomy and academic autonomy. While operational autonomy can be surrendered if the researchers perceive the benefits as great and academic autonomy is not easily given up, especially in the case of senior researchers.

$\mathrm{Ph}$.D. researchers face different choices, and firms can negatively influence their autonomy when their research is delayed for instance by requirements to perform operational tasks for the industry partner. Academic autonomy is perceived as a dimension of scientific integrity. Partnership formalisation was not seen as destructive-indeed, it was considered to be fairly beneficial if the research methodology was not compromised. Managing operational and academic autonomy may prove to be the key to managing U-I research partnerships. This insight may help firms to understand how researchers work.

A further means to secure autonomy in U-I relationships may be the use of open data partnerships (Perkmann and Schildt 2015). Here, a boundary organisation acts as a bridge between firms and university researchers. This facilitates the pursuit of purely academic issues, solving researchers' need for autonomy. We are aware of open data partnerships in science, technology, engineering and mathematics research, but none as yet in the social sciences. Initiatives such as the Twitter data grant (Twitter 2014) may be a move in such a direction. 


\subsection{Limitations and future research}

This study has limitations, which can be addressed in future research. The study calls for more longitudinal data. We collected cross-sectional data and were retrospectively able to capture the research process from the early stage when research questions and research partners were determined through research execution. Nonetheless, longitudinal data on the different stages would add value to the analysis. Also, the number of cases don't allow one to generalise the results. More researchers from different contexts should be analysed.

Since we investigated individual research projects rather than sequences of research projects, we are not yet in a position to make full use of Bingham's (2009) ideas on the performance implications of combinations of strategically oriented and opportunity-driven behaviour across a temporal sequence of research projects. We can say that most of the projects were performing well, according to the interviewees. Thus, we can conclude with some assurance that researchers should behave in Mode 3 (strategically planned way) in project selection to gain as much as possible from industry-sponsored projects. Whether these positive effects of strategic project selection hold or indeed increase over a project remains a question for future research.

Further, conflicts over resource interdependence did not appear in the cases we investigated. For instance, none of the corporate partners claimed exclusive IP on the research results, nor did corporate supervisors claim unwarranted authorship of the academic output. These cases are known in other research fields (Murray 2010) and may also exist in the social sciences. If this is the case, an investigation of U-I exchange strategies can further corroborate Murray's (2010) results and set out implications for the management of such cooperation.

Finally, we cannot corroborate our results on firms' perspective. To do so would make it necessary to test whether the behaviour modes and behaviours in the opportunity selection and execution phases affect U-I partnerships' performance. With such results to hand, we would be able to formulate practical recommendations regarding research management and policy. To further develop this framework of researcher strategic behaviours, a measure of alliance performance based on the extent to which goals are attained (Bamford et al. 2004; Kale and Singh 2009) would be helpful.

Acknowledgements The authors would like to thank the two anonymous reviewers for their constructive comments on the paper. We also would like to acknowledge the work of Björn Janßen on which this paper builds.

Open Access This article is distributed under the terms of the Creative Commons Attribution 4.0 International License (http://creativecommons.org/licenses/by/4.0/), which permits unrestricted use, distribution, and reproduction in any medium, provided you give appropriate credit to the original author(s) and the source, provide a link to the Creative Commons license, and indicate if changes were made. 


\section{References}

Agrawal A, Henderson R (2002) Putting patents in context: exploring knowledge transfer from MIT. Manag Sci 48:44-60

Bamford J, Gomes-Casseres B, Robinson M (2004) Envisioning collaboration: mastering alliance strategies. Jossey-Bass, San Francisco

Bingham CB (2009) Oscilating improviazation: How entrepreneurial firms create success in foreign markets over time. Strateg Entrep J 3:321-345

Bingham CB, Furr NR, Eisenhardt KM (2014) The opportunity paradox. MIT Sloan Manag Rev $56: 29-35$

Bingham CB, Heimeriks KH, Schijven M, Gates S (2015) Concurrent learning: how firms develop multiple dynamic capabilities in parallel. Strateg Entrep J 36:1802-1825

Casciaro T, Piskorski MJ (2005) Power imbalance, mutual dependence, and constraint absorption: a closer look at resource dependence theory. Adm Sci Q 50:167-199

D'Este P, Patel P (2007) University-industry linkages in the UK: what are the factors underlying the variety of interactions with industry? Res Policy 36:1295-1313

D'Este P, Perkmann M (2010) Why do academics work with industry? The entrepreneurial university and individual motivations. J Technol Transf 36:316-339

Estrada I, Faems D, Martin Cruz N, Perez Santana P (2016) The role of interpartner dissimilarities in Industry-University alliances: insights from a comparative case study. Res Policy 45:2008-2022

Fereday J, Muir-Cochrane E (2006) Demonstrating rigor using thematic analysis: a hybrid approach of inductive and deductive coding and theme development. Int J Qual Methods 5:80-92

Gibbons M, Limoges C, Nowotny H, Schwartzmann S, Scott P, Trow M (1994) The new production of knowledge. The dynamics of science and research in contemporary societies. SAGE publications, Stockholm

Gläser J, Laudel G (2013) Life with and without coding: two methods for early-stage data analysis in qualitative research aiming at causal explanations. Qual Soc Res Sozialforschung 14: art.5

Hackman JR, Oldham GR (1975) Development of job diagnostic survey. J Appl Psychol 60:159-170

Haspeslagh PC, Jemison DB (1991) Managing acquisitions: creating value through corporate renewal. The Free Press, New York

Janßen B (2016) University-industry research partnerships: a research exploring the dynamics of university-industry interaction with mutual research projects. Unviersity Twente press, Enschede

Kale P, Singh H (2009) Managing strategic alliances: what do we know now, and where do we go from here? Acad Manag Perspect 23:45-62

Kurek K, Geurts PATM, Roosendaal HE (2007) The research entrepreneur. Strategic positioning of the researcher on the societal environment. Sci Public Policy 34(7):501-513

Lee HF, Miozzo M (2015) How does working on university-industry collaborative projects affect science and engineering doctorates' careers? Evidence from a UK research-based university. J Technol Transf 40:293-317

Louis KS, Blumenthal D, Gluck ME, Stoto MA (1989) Entrepreneurs in academe: an exploration of behaviours among life scientists. Adm Sci Q 24:110-131

Mayring P (2000) Qualitative Inhaltsanalyse. Deutscher Studien-Verlag, Weinheim, Grundlangen und Techniken

Merton RK (1957) Priorities in scientific discovery: a chapter in the sociology of science. Am Sociol Rev 22:635-659

Mora-Valentin EM, Montoro-Sanchez A, Guerras-Martin LA (2004) Determining factors in the success of RandD cooperative agreements between firms and research organizations. Res Policy 33:17-40

Murray F (2010) The oncomouse that roared: hybrid exchange strategies as a source of distinction at the boundary of overlapping institutions. Am J Sociol 116:341-388

Olmos-Penuela J, Castro-Martinez E, D'Este P (2014) Knowledge transfer activities in social sciences and humanities: explaining the interactions of research groups with non-academic agents. Res Policy 43:696-706

Perkmann M, Schildt H (2015) Open data partnerships between firms and universities: the role of boundary organizations. Res Policy 44:1133-1143

Perkmann M, Walsh K (2007) University-industry relationships and open innovation: towards a research agenda. Int J Manag Rev 9:259-280 
Perkmann M, Walsh K (2008) Engaging the scholar: three types of academic consulting and their impact on universities and industry. Res Policy 37:1884-1891

Perkmann M, Neely A, Walsh K (2011) How should firms evaluate success in university-industry alliances? A performance measurement system. R\&D Manag 41:202-216

Perkmann M et al (2013) Academic engagement and commercialisation: a review of the literature on university-industry relations. Res Policy 42:423-442

Pfeffer J, Salancik G (1978) The external control of organizations: a resource dependency perspective. Harper \& Row, New York

Ramos-Vielba I, Sanchez-Barrioluengo M, Wooley R (2016) Scientific research groups' cooperation with firms and government agencies: motivations and barriers. J Technol Transf 41:558-585

Salimi N, Bekkers R, Frenken K (2015) Governance mode choice in collaborative PhD projects. J Technol Transf 40:840-858

Steinmo M, Rasmussen E (2015) How firms collaborate with public research organizations: the evolution of proximity dimensions in successful innovation projects. J Bus Res 69(3):1250-1259

Stokes DE (1997) Pasteur's quadrant—basic science and technological innovation. Brookings Institution Press, Washington

Trevelyan R (2001) The paradox of autonomy: a case if academic research scientists. Hum Relat 54:495-525

Twitter (2014) Introducing twitter data grants. https://blog.twitter.com/engineering/en_us/a/2014/intro ducing-twitter-data-grants.html. Accessed 31 Oct 2019

Van Looy B, Ranga M, Callaert J, Debackere K, Zimmermann E (2004) Combining entrepreneurial and scientific performance in academia: towards a compounded and reciprocal Matthew-effect? Res Policy 33:425-441

Wilts A (2000) Forms of research organisation and their responsiveness to external goal setting. Res Policy 29(6):767-781

Zalewska-Kurek K (2016) Understanding researchers' strategic behaviour in knowledge production: a case of social science and nanotechnology researchers. J Knowl Manag 20:1148-1167

Zalewska-Kurek K, Geurts P, Roosendaal H (2010) The impact of autonomy and interdependence of individual researchers on their production of knowledge and its impact: an empirical study of a nanotechnology institute. Res Eval 19:217-225

Zalewska-Kurek K, Egedova K, Geurts PATM, Roosendaal HE (2016) Knowledge transfer activities of scientists in nanotechnology. J Technol Transf. https://doi.org/10.1007/s10961-016-9467-6

Publisher's Note Springer Nature remains neutral with regard to jurisdictional claims in published maps and institutional affiliations. 